\title{
The Digital Turn: staff perceptions of the virtual learning environment and the implications for educational developers
}

\author{
Nuala Harding, Athlone Institute of Technology
}

\begin{abstract}
Virtual Learning Environments (VLEs) have become a critical part of the Higher Education (HE) learning, teaching and assessment environment over the past two d ecades. The study in this paper complements the longitudinal study designed by the \#VLEIreland Project team to examine the key drivers and barriers for uptake and usage of an institutional VLE amongst students. There is a dearth of literature on VLE usage by staff in an Irish context. The findings of the \#VLEIreland staff survey, presented in this paper, help us understand staff usage of technology tools including the VLE, and places this in a wider context. In 2014, the project team developed an electronic survey instrument to examine staff perceptions of the VLE and online learning tools. This collaborative study involved seven Irish HE institutes. There were 580 respondents to the electronic survey. Findings show lack of time as a considerable barrier to staff usage of the VLE and that staff usage is primarily for distribution of resources, communication and assignment submission. However, insights can also be gleaned from the data to assist educational developers when designing appropriate interventions for the development needs of staff. When considered in conjunction with findings from student data, the common misconceptions about VLE usage can be addressed including a negative impact on attendance and over-reliance on lecturers. In addition, consideration for the professionalisation of teaching in terms of digital literacy and technological skills is considered of vital importance to empower staff in the era of the digital turn.
\end{abstract}

Irish Journal of Technology Enhanced Learning Ireland, 2018. @ 2018 Harding, N. The Irish Journal of Technology Enhanced Learning Ireland is the journal of the Irish Learning Technology Association, an Irishbased professional and scholarly society and membership organisation. (CRO\# 520231) http://www.ilta.ie/. This is an Open Access article distributed under the terms of the Creative Commons Attribution 4.0 International License (http://creativecommons.org/licenses/by/4.0), allowing third parties to copy and redistribute the material in any medium or format and to remix, transform, and build upon the material for any purpose, even commercially, provided the original work is properly cited and states its license. 


\section{Introduction}

\subsection{Context}

Since the mid-1990s, higher education in Ireland and internationally has seen the emergence of digital technologies including the introduction of virtual learning environments (VLEs) across the sector. These developments in the increasing use of technologies have been identified as "the digital turn" (Jones, 2013, p. 169), which requires increased attention to new literacy practices in digital environments across a variety of social contexts including educational, recreational sites and workplaces. In addition, this decade saw the establishment of centres of learning and teaching in Ireland, initially in the universities funded by the HEA and more recently across the sector responding to staff development requirements including the use of the VLE.

Key policy developments have also influenced the work of centres for teaching and learning, including the National Strategy for Higher Education to 2030 (DES, 2011). The subsequent establishment of the National Forum for the Enhancement of Teaching and Learning led to the publication of the Roadmap for Enhancement in a Digital World 2015-2017 (National Forum, 2015). More recently the National Forum has published the National Professional Development Framework (National Forum, 2016). This incorporates a specific domain entitled "Personal and Professional Digital Capacity" focusing on "the importance of personal and professional digital capacity and the application of digital skills and knowledge to professional practice" and appropriate to this study, "to the development of personal confidence in digital skills to develop professional competence and the identification of opportunities for technology to support and enhance student learning" (National Forum, 2016, p. 7). This approach is in keeping with European Commission objectives for improving teaching and learning (European Commission, 2013).

Much attention has recently focused on the lack of investment in technological infrastructure with a variety of negative consequences (National Forum, 2017). These include the limitations on educators' endeavours to be innovative and a lack of access to up-to-date technologies, which it is suggested is contributing to slippage in university rankings. Indeed, expert commentators have requested a rethink of the role of educators in the digital era and of the funding model that currently applies to Irish higher education institutions (HEIs) (Humphries, 2015). It would seem that Bonk's (2004) suggestion that we are facing a perfect 'eStorm' linking pedagogy, technology and learner needs' remains relevant today in the current context of Irish HE and also in particular to this research study.

The \#VLEIreland staff survey has been described elsewhere in this Special Issue (Farrelly, Raftery \& Harding, 2018; McAvinia \& Risquez, 2018). Analysis of this data indicates VLE usage and barriers to use, and from this we can identify staff development needs. The need for research into the challenges faced by learners and teachers in pursuing learning goals using technology provides justification for this study, which focuses primarily on staff perceptions of the VLE and the implications of these for educational developers.

\subsection{The digital turn}

Consideration of the place of the VLE implies consideration of the nature of the 'digital unviersity' and 'digital turn'. The definition of a 'digital university' is contested but may be considered to apply to "all university functions as they are revised to make use of digital technologies and to accommodate their impacts" (Jones, 2013, p. 164). These include the use of technology such as the VLE to enhance learning. However, even in 2004, Zemsky and 
Massey's report of the Weathervane Project and the use of the VLE suggested that "any expectation that such technologies would of themselves bring about change in teaching practices was unfounded" (O'Rourke, Rooney, \& Boylan, 2015, p. 3). Indeed, Selwyn suggests that digital technologies have created increased "managerialism" in universities affecting students in addition to academic and administrative staff (2014b). Weller's pronouncement of the death of the VLE received widespread acclaim in 2007, but a decade later the VLE remains mission critical to most HEIs. While the VLE gives the security provided by 'walled garden models' favoured by students and academics, it has also been suggested that the VLE can reduce experimentation by students and staff (Conole \& Alevizou, 2010, p. 84). There are still those who do not engage with the VLE, contrasting with the early adopters of technologies in all aspects of academic work.

\subsection{The "digital natives" debate}

Several authors have posited the idea that the current young generation, born after 1990 and often referred to as generation Z (Williams, 2015), have a familiarity with the networked world and in particular social media, and that this phenomenon has implications for teaching in higher education. The terms 'digital native' and 'digital immigrant' (Prensky, 2001) have been used to indicate the differences between those who have grown up with computers and the internet which can set them in opposition to their teachers who are older and may not have the same proficiency (Bayne \& Ross, 2007). These students are presumed to be more at ease with technology and some would suggest this places an imperative on teachers to respond and remain relevant (Bayne \& Ross, 2007). According to some authors, digital natives' familiarity with technology automatically implies they think and learn differently compared with previous generations (Howe \& Strauss, 2000; Prensky, 2001, 2010; Oblinger \& Oblinger, 2005; Palfrey \& Gasser, 2008; cited in Jones, 2013, p.167). However, Jones suggests that such high skill levels do not translate into preferences for increased use of technology in the classroom and indeed he also suggests that student attitudes towards teaching can be on the contrary, quite conventional (Jones, 2013, p. 167). Selwyn has also argued that the hype and optimism normally associated with educational technologies should be challenged (2014a). Recognising the importance of this debate, our findings in relation to student perceptions of the VLE (Raftery \& Risquez, 2018; Ryan \& Risquez, 2018) indicate that "student satisfaction with the VLE is intrinsically linked with the educational design behind the use of the tools". It appears that the VLE offers benefits to students, particularly support for students with specific learning difficulties especially when adopting a multimodal approach in the design of learning materials and activities (Caruso \& Kvavik, 2005; McMahon, 2016). Nonetheless, a more considered examination of the factors influencing attendance at lectures is required (Risquez et al., 2013). Our previous findings also indicate that use of the VLE changed students' patterns of learning, providing them with more flexible ways of studying (Risquez et al., 2013). Therefore, researching staff perceptions of the VLE is important in understanding how they might use it to enhance student learning.

\subsection{Digital literacy}

Recent discussion of digital literacy has moved away from the concept of a narrow set of ICT skills towards the development of knowledge and competence (Aviram \& Eshet-Alkalai, 2006). More recently other scholars suggest that digital literacy is a foundational capability essential for participation within society (Littlejohn, Beetham, \& McGill, 2013). JISC defines digital literacies as "those capabilities which fit an individual for living, learning and working in a digital society" (2014). JISC include seven elements to indicate the capabilities 
encompassed including: information literacy, media literacy, ICT literacy, learning skills, communication and collaboration, career and identity management and digital scholarship (JISC, 2014). Each of these seven elements can be considered relevant to this study as the development of digital literacies could be mediated through the VLE. The VLE can be used throughout a programme of study to assist students manage their digital reputation and online identity; use digital applications; develop effective study and learning skills, participate in emerging professional and research practices, develop critical skills in relation to finding, sharing information, and collaborate and communicate using a variety of media and networks (JISC, 2014). This provides another lens to critique the findings of this study, particularly when examining the reported use of online tools including the VLE and staff requirements for further continuous professional development in the use of such tools with a view to embedding digital literacies as part of curriculum design and pedagogic practice.

\subsection{Research questions}

In order to examine the use of the VLE and online tools by HE staff as a social phenomenon with an objective reality the following research questions were devised for this study:

(a) To what extent are staff using the VLE and online learning tools and what are the barriers to use reported by staff?

(b) What are the implications for educational developers arising from the perceptions of staff relating to VLE use and non-use?

\section{Methodology}

Previous papers in this Special Issue have described the methodology and data analysis procedures of the \#VLEIreland Project (Farrelly, Raftery \& Harding, 2018; McAvinia \& Risquez, 2018; Ryan \& Risquez, 2018). The staff survey instrument consisted of questions designed to generate categorical data relating to the research questions. Question types included dichotomous, multiple choice, Likert-scale questions and open-ended comments. The research was conducted in keeping with best practice in educational research (BERA, 2011).

\section{Findings and discussion: staff perception of the VLEs}

\subsection{Demographics: staff profiles and the use of the VLE}

Of the 580 respondents to the survey $10 \%(n=59)$ indicated they did not use the VLE (Figure 1). Of those who indicated they used the VLE the majority $79 \%(n=451)$, held a teaching role with the breakdown as follows Professor $(n=28)$, Senior Lecturers $(n=83)$, Lecturers $(n=258)$ or Junior (Assistant Lecturers) $(n=82)$. Other respondents who indicated they use the VLE as part of their role included, post and pre-doctoral researchers and postgraduate teaching assistants $(\mathrm{n}=16)$ and one administrator. $8 \%(\mathrm{n}=48)$ of respondents who indicated they were non-users held an academic role, with the majority either Senior lecturers or Junior (Assistant) Lecturers $(n=41)$. 


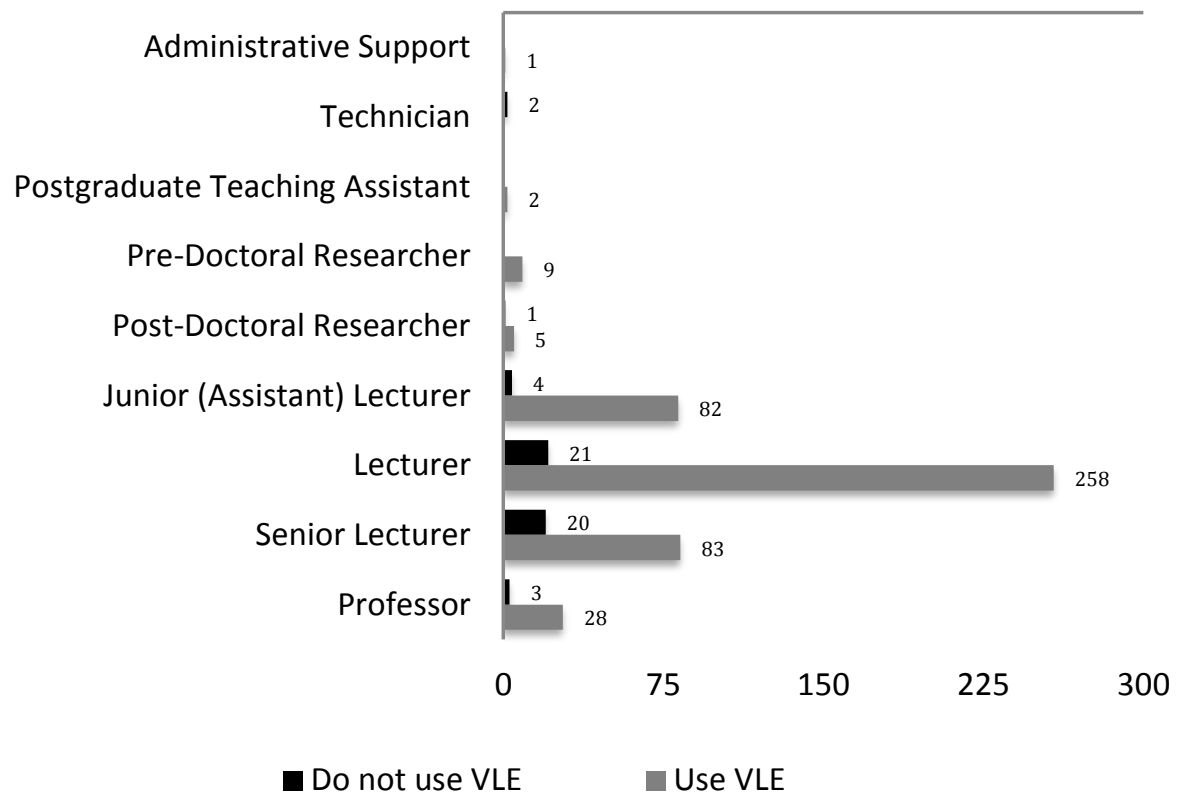

Figure 1: Respondent use and non-use of the VLE according to role

Respondents were asked to indicate gender, however gender bias was evident (Figure 2).

- Use VLE Do not use VLE

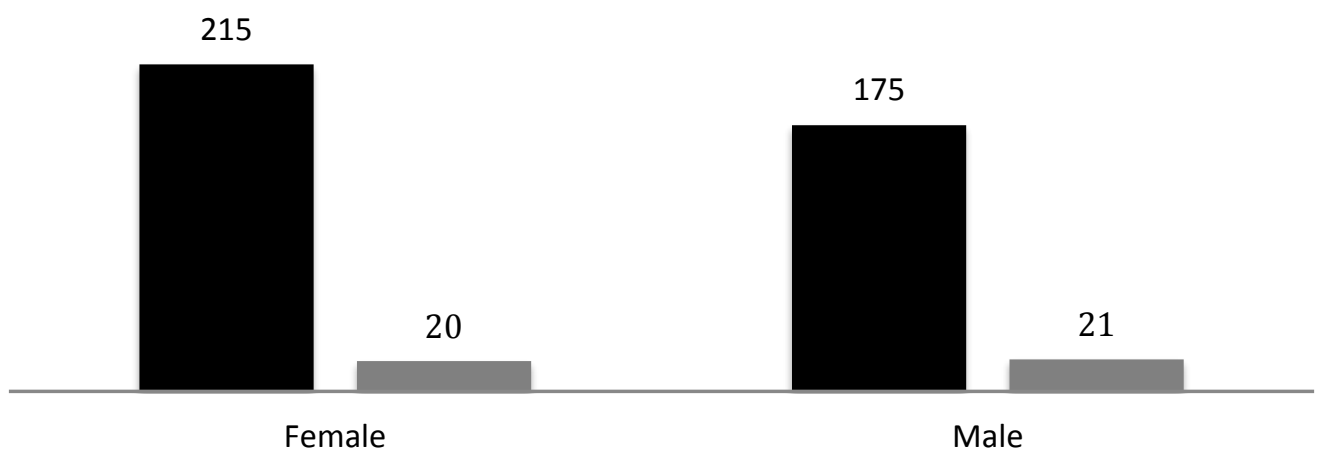

\section{Figure 2: Use and non-use by gender}

When asked to indicate how long respondents have been using the VLE, 44\% reported using the VLE for more than five years, $(n=200)$ with a further $38 \%$ indicating usage for two years or more and $18 \%(n=80)$ reporting using it for less than two years (Figure 3 ). 


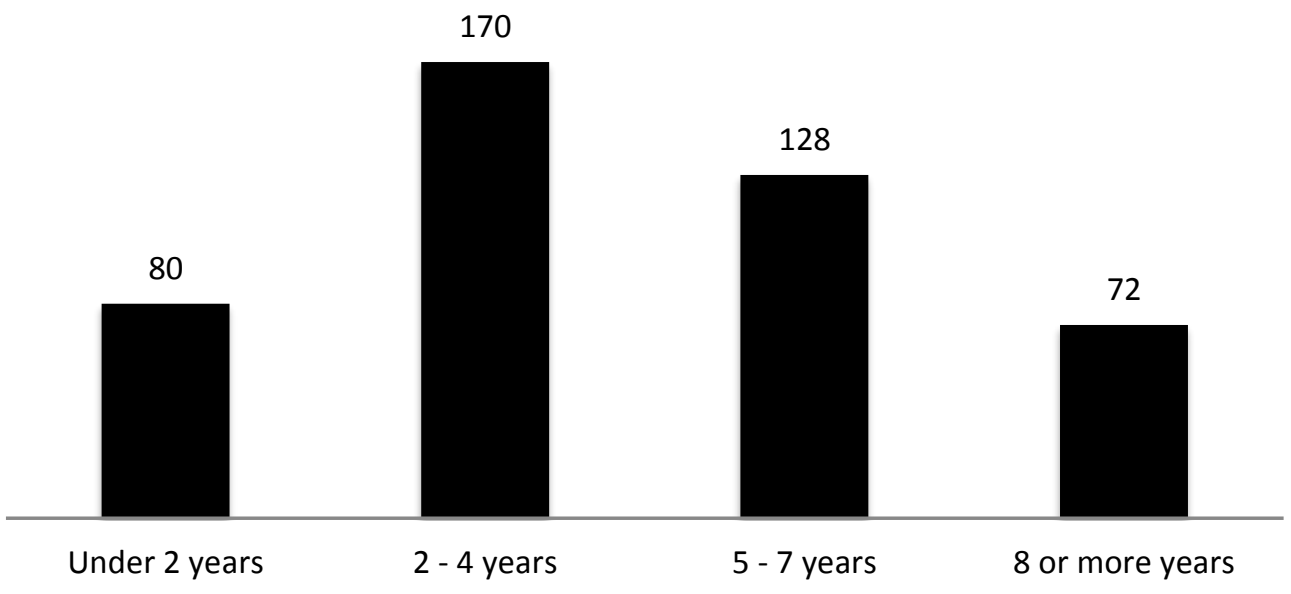

\section{Figure 3: Use of VLE in years}

$67 \%$ of respondents $(n=355)$ indicated they had received training in using the VLE, $33 \%$ $(n=172)$ indicated they had not (Figure 4). This finding has implications for the supports offered to staff and the lack of opportunities and/or time to engage in development.

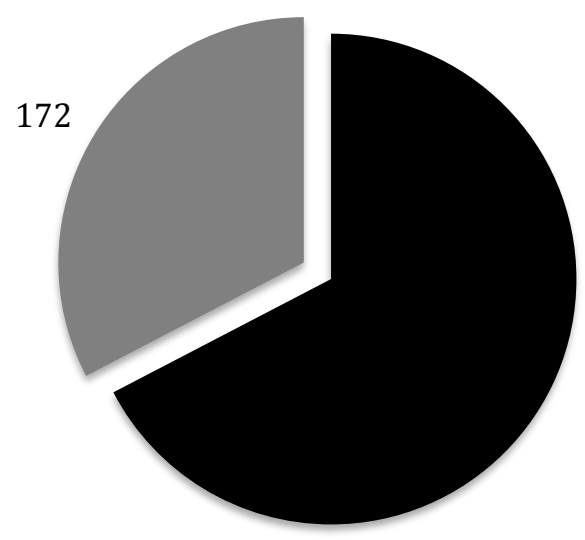

Figure 4: Training in the use of the VLE

\subsection{Non-users: barriers to use and suggestions}

Non-users were asked to indicate what would encourage them to use the VLE in the future. Of the 59 non-user survey responses, 48 responded to this question. When analysed thematically the responses generally split into two categories, barriers to use and suggestions to encourage future use (Table 1). Usability was the main barrier to use with some very strong comments about the design of VLEs. In addition, some respondents were of the view that the VLE did not enhance teaching or was not appropriate to teaching in their discipline. One respondent mentioned that "teaching happened in the classroom". This may reflect non- 
user theoretical perspectives and current understanding of the process of teaching and in particular of learning as something that only happens in the classroom. However, it may also relate to the views articulated by Satchwell, Barton and Hamilton (2013) when they suggest use of technology when appropriate and suited to the context. In addition, "ownership of resources" after development arose as a concern. In relation to suggestions to encourage future use, training received the most responses with some examples of types of supports required (Table 2). These findings will inform and assist developers when designing training. "Time" emerged as both a barrier to use and a suggestion to support future use. This also emerged as key finding as it consistent with the data for VLE users and is discussed further in McAvinia, Ryan and Moloney (2018) when analysing the talk of time in lecturers' use of the VLE.

Finally, the "teaching environment" emerged as a theme. Responses included having to conform to peer pressure and mandating use of the VLE. Interestingly, one respondent indicated they would use the VLE if teaching a distance course, again indicating a belief that it is not required for teaching that primarily involves face-to-face classroom contact. This may indicate that the respondents do not consider the development of digital literacies as a requisite learning outcome for their students in the modules they teach, even though JISC's research suggests students will look to their lecturers to recommend the technologies required for their subject and use technologies that are embedded in the curriculum (JISC, 2015). 


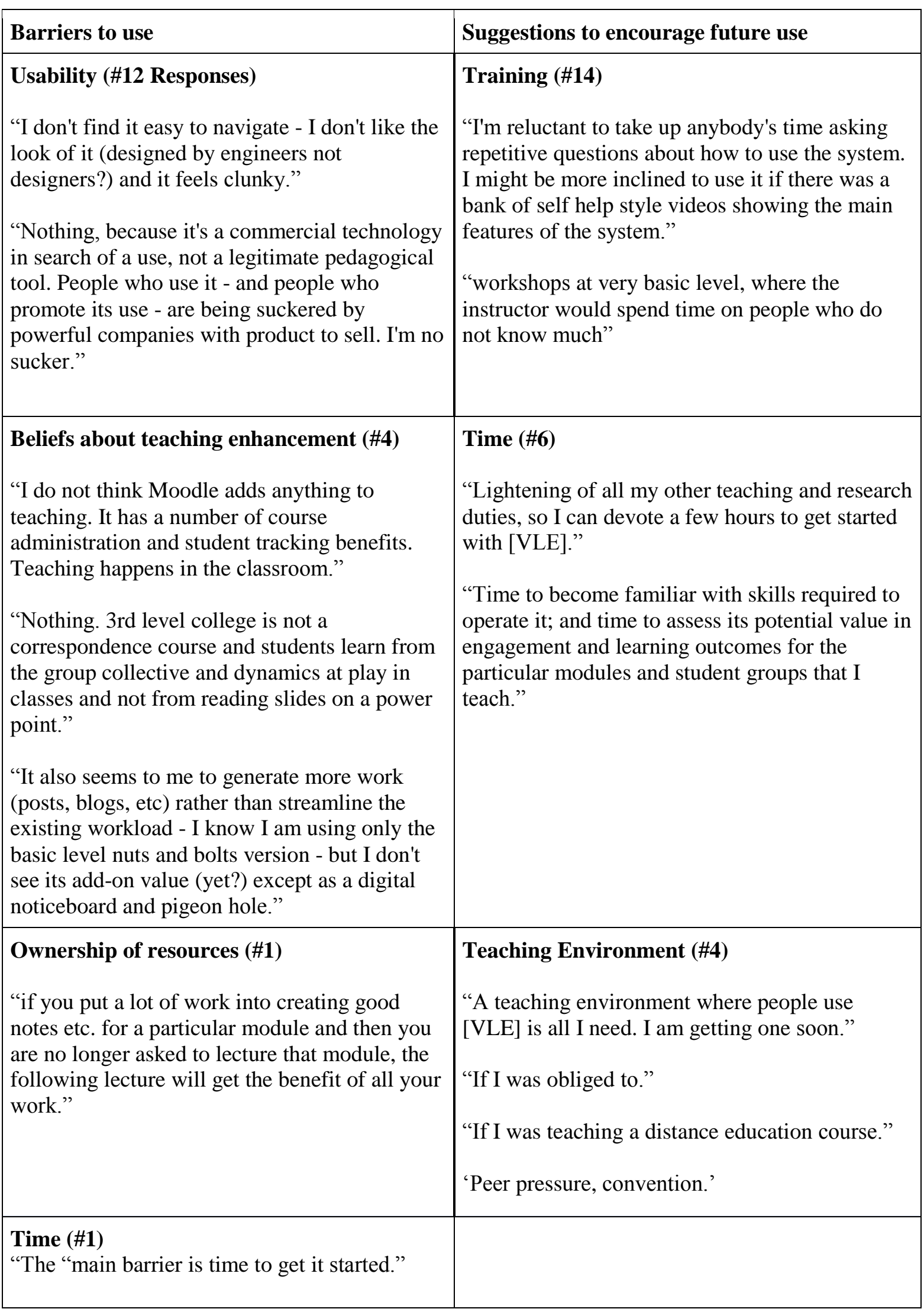

Table 1: What would encourage you to use the VLE? 


\subsection{Barriers or restrictions to the use of the VLE}

Three key findings emerged in response to statements relating to barriers to using the VLE or other online tools (Figure 5). When asked to respond to the statement 'Training is available but is not suited to my requirements', $33 \%(n=177)$ disagreed or strongly disagreed with this statement and 29\% ( $\mathrm{n}=132)$ agreed or strongly agreed. This is in contrast to the positive response to adequacy of training reported earlier, which has implications for educational developers.

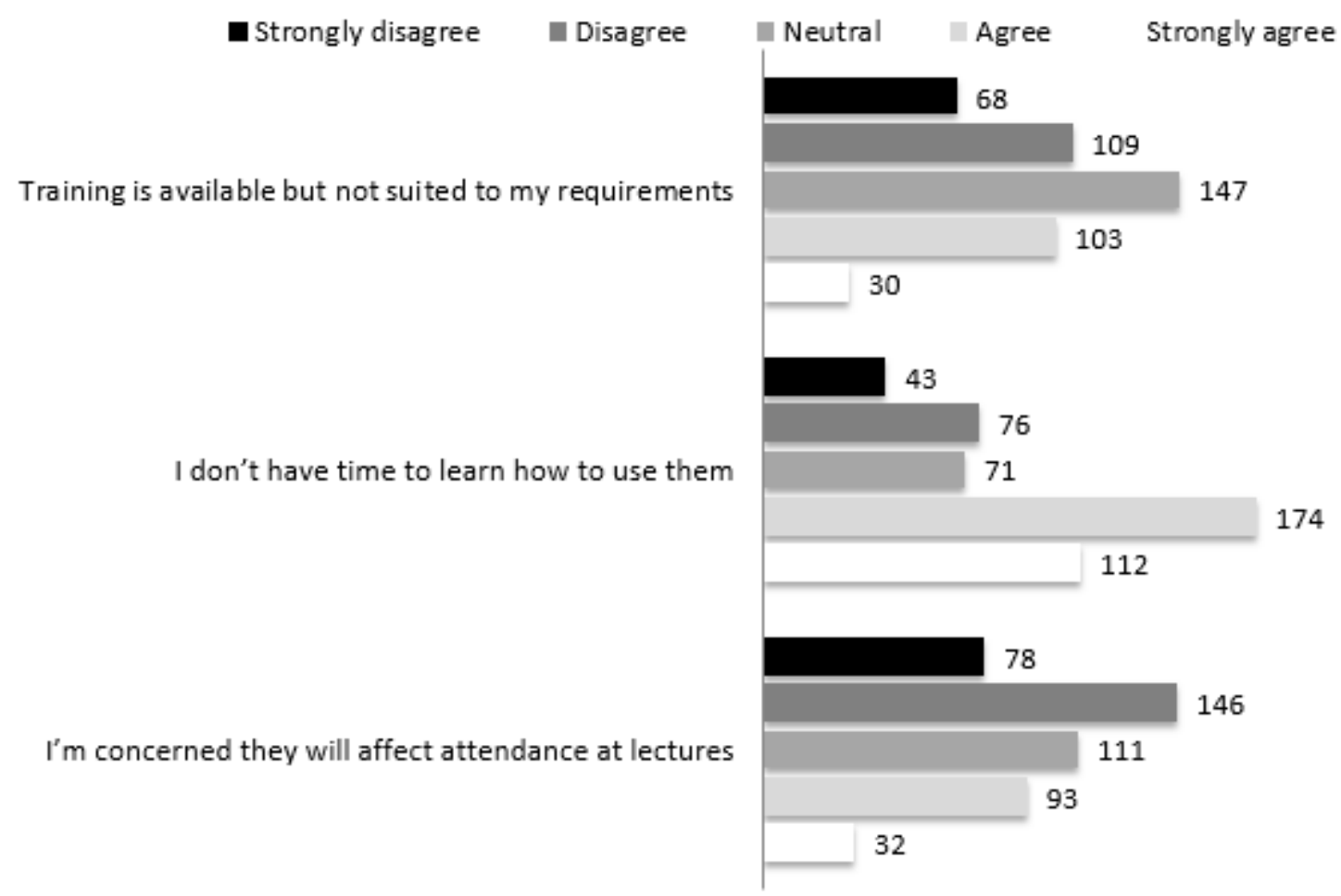

Figure 5: Barriers or restrictions to use of VLE and online tools

Importantly, when asked to respond to the statement 'I don't have the time to learn how to use them' $60 \%(n=286)$ of respondents indicated they agreed or strongly agreed with this statement. $25 \%(\mathrm{n}=119)$ indicated they disagreed or strongly disagreed with this statement with $15 \%(\mathrm{n}=71)$ remaining neutral. Time emerged as a key theme in the analysis of the qualitative data also in the responses given to different open questions (Table 2).

\begin{tabular}{|l|l|}
\hline & $\begin{array}{l}\text { Number of respondents } \\
\text { suggesting 'time' }\end{array}$ \\
\hline $\begin{array}{l}\text { Is there anything that prevents you getting best use of the } \\
\text { VLE? }\end{array}$ & 135 \\
\hline $\begin{array}{l}\text { Are there any other reasons you choose not to, or are } \\
\text { prevented from, making use of online tools in your teaching? }\end{array}$ & 77 \\
\hline
\end{tabular}

Table 2: Time as a factor 
This finding is in keeping with the responses by non-users and also with earlier studies. Goodyear (2005) suggests that in terms of introducing innovations in learning design and technology, academic staff maintain a strong sense of being "time-poor" (in Laurillard, 2008, p. 144). Indeed, Brownell and Tanner posit that there is a substantial body of literature indicating the many factors that impede faculty change, the most common of which are a "lack of training, time, and incentives" (2012, p. 339). However, they also contend that professional identity plays a key role in being open to pedagogic change and contend that academics particularly are often reluctant to "come out as teachers" (2012, p. 342). These findings have implications for educational developers in terms of their role in policy development, designing guideline documents and the development of initiatives in professional development. For example, when working with newly appointed staff Clay (2010) suggests a five stage model which commences with uploading of resources (stage one) and continues with advanced use on a weekly basis such as adding a variety of learning resources; photographs of classroom based exercises, links to eBooks and RSS feeds (stage two); following this the addition of interactivity through online quizzes and feedback (stage three); engagement follows this approach using online forums (stage 4) and finally embedding is the feature of the final stage, where usage of the VLE and online tools becomes part of practice and practitioners are able to offer blended learning (stage five). This model progresses staff beyond the use of the VLE as a document repository and assignment submission site to one that supports learning through designing in interactivity thereby supporting student engagement in the learning process. Interestingly, the affordances of technology to enable feedback, particularly for first year undergraduates, have also been identified as a key means to support learning (Y1 Feedback 2016a, 2016b). However evidence of extensive practice is not apparent in this study.

\subsection{Attendance at lectures}

When asked to respond to the statement 'I am concerned [the VLE] will affect attendance at lecturers' $27 \%(\mathrm{n}=125)$ indicated that they agreed or strongly agreed with this statement. However, $49 \%(n=224)$ disagreed or strongly disagreed with the statement and 24\% $(n=111)$ remained neutral. When considered in conjunction with the findings from the study of student perceptions (Ryan \& Risquez, 2018), again this sets a challenge to educational developers to assist staff in providing appropriate resources and extending the use of the VLE beyond a document repository (Risquez, et al., 2013). In addition, this finding may also relate to students' reported dissatisfaction with inconsistent use by lecturers (Cosgrave, et al., 2011; O'Rourke et al., 2015) which has implications for the development of policy and strategic planning at macro, meso and particularly at micro level within academic departments by integrating programme-wide approaches when integrating the VLE into learning, teaching and assessment strategies.

\subsection{Restricted use of the VLE}

When asked to rate the features of the VLE that respondents considered very useful and useful, a specific pattern emerges (Figure 6). Over $40 \%$ of usage relates to distribution of resources, communication, submission of assignments, giving grades/marks and finally for the use of text-matching software. 


\section{N Harding}

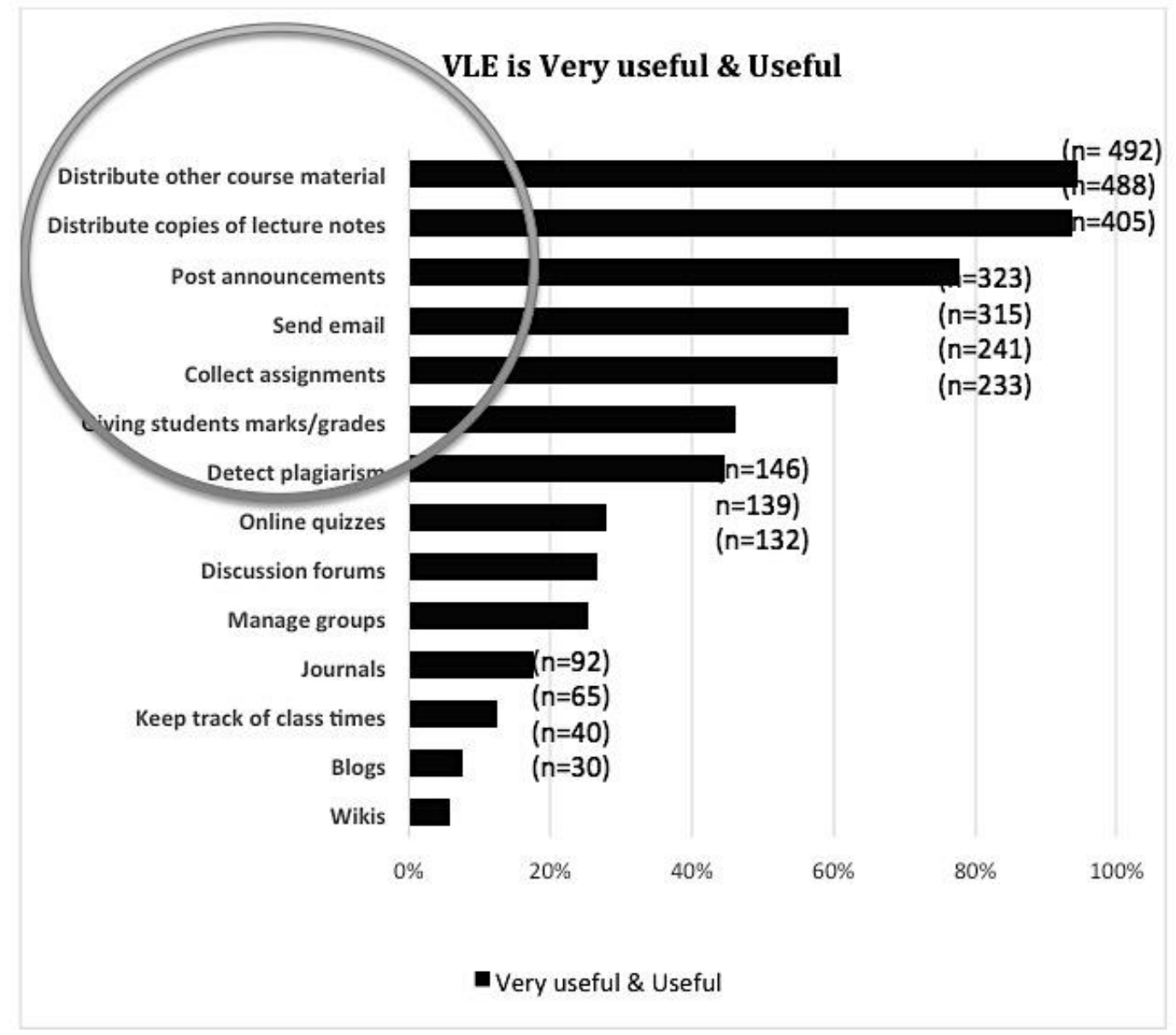

Figure 6: Rate the features of the VLE

The data was examined further using Pearson correlation to produce the strength of a linear association between the two variables, 'perceived usefulness of the VLE' and the 'features used' (Figure 7). 


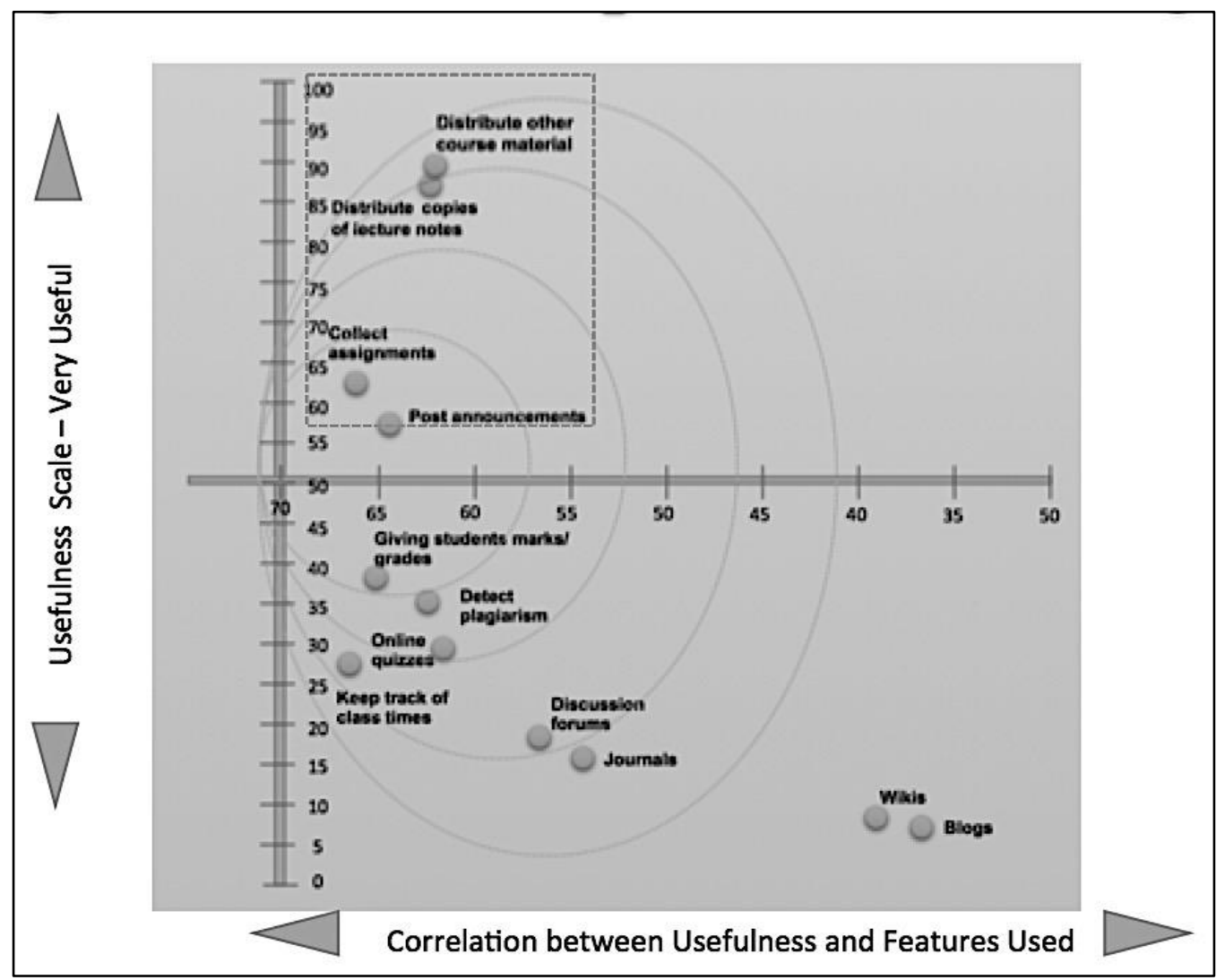

Figure 7: Relationship between perceived usefulness and VLE features used

The left axis shows the scale for perceived usefulness with anything above the intersecting line being very useful. The features are then plotted according to how they correlate with perceived usefulness. This replicates and confirms the findings outlined in Figure 6.

However, it may also offer a reason for staff not moving beyond the basic use of the VLE or indeed extensive change to practice, as suggested in other studies (Greener, 2012; O'Rourke et al., 2015). It also raises questions in relation to the use of technology to enhance learning as, if staff do not consider the features of the VLE which promote active and peer to peer learning as useful to their teaching and student learning, this has implication for the use of all technologies. This relates to their underlying beliefs about teaching and may go some way to explain why some uncritically adopt technologies whilst others reject them uncritically (Bayne \& Ross, 2007). Indeed, Margaryan, Littlejohn and Vojt (2011) suggest that even academics who are proficient in the use of technology for research find it difficult to integrate technology-enhanced learning into their teaching practice (cited in Littlejohn, et al., 2013, p. 128). The finding also provides further evidence for educational developers to consider how staff are introduced to classroom technology, and if the focus is on skills acquisition without also focusing on how technology can be used appropriately to enhance the development of digital literacies of students.

\subsection{Use of online tools}

The survey was designed to elicit responses in relation to the use of online tools and techniques in the year prior to completion. A selection of options was provided with respondents indicating whether or not they used them and if they did was it inside or outside of the VLE. Table 4 displays the findings with any element achieving a response $80 \%$ and over highlighted in red. A similar trend of conservative use emerges, as indicated earlier, with 


\section{N Harding}

the VLE being used primarily for sharing resources, communication, assignment submission and plagiarism detection. This finding is in keeping with Greener who suggests that use of the VLE by the lecturer does not progress beyond this basic requirement (2012).

\begin{tabular}{|c|c|c|c|}
\hline $\begin{array}{l}\text { What online tools and techniques have you used in the } \\
\text { past year? } \\
\# 450-500 \\
\text { Grey }=80 \% \text { and over of respondents }\end{array}$ & $\begin{array}{l}\text { Yes, } \\
\text { within } \\
\text { [VLE] }\end{array}$ & $\begin{array}{l}\text { Yes, } \\
\text { outside } \\
\text { [VLE] }\end{array}$ & $\begin{array}{l}\text { No, do } \\
\text { not use }\end{array}$ \\
\hline Assignment submission & 318 & 67 & 109 \\
\hline Plagiarism detection using Turnitin/SafeAssign & 239 & 62 & 186 \\
\hline $\begin{array}{l}\text { Access to external web based resources or digital } \\
\text { repositories }\end{array}$ & 223 & 130 & 143 \\
\hline Videos and screencasts & 157 & 108 & 223 \\
\hline $\begin{array}{l}\text { Online assignment feedback-Turnitin/SafeAssign/Inline } \\
\text { Grading }\end{array}$ & 146 & 46 & 280 \\
\hline $\begin{array}{l}\text { Asynchronous Collaborative tools e.g. discussion boards, } \\
\text { blogs, wikis }\end{array}$ & 113 & 47 & 320 \\
\hline Online quizzes (formative, for feedback) & 108 & 48 & 330 \\
\hline Audio/Video Lecture recordings & 106 & 81 & 291 \\
\hline Online quizzes (summative, for marks) & 96 & 29 & 357 \\
\hline Online journal tool & 59 & 34 & 379 \\
\hline Online student presentations (individual \& group) & 45 & 71 & 352 \\
\hline Podcasts & 44 & 65 & 358 \\
\hline $\begin{array}{l}\text { Synchronous Collaborative tools (virtual classroom, } \\
\text { Skype etc.) }\end{array}$ & 37 & 63 & 368 \\
\hline e-portfolio/PDP/progress files & 27 & 37 & 403 \\
\hline Peer assessment tools & 22 & 61 & 383 \\
\hline Simulations and games & 15 & 55 & 391 \\
\hline
\end{tabular}

Table 3: Use of online tools inside and outside of VLE 


\subsection{Identification of development needs - implications for developers}

This finding raises interesting questions about the perceived usefulness of technologies in and outside of the VLE with a similar picture of conservative use emerging for outside. It would appear that usage of online tools whether inside or outside the VLE is predominantly at stage one and two of the Clay's model (2010). This again highlights the need for critical engagement with how to support the development of digital literacies amongst staff and students, the development of policy and practice and the provision of appropriate professional development opportunities, in keeping with recent strategic documents (DES, 2011; JISC, 2014; JISC, 2015; European Commission, 2013). Consideration in this regard is also required in relation to embedding digital literacies in curriculum design throughout programmes (JISC, 2014; JISC, 2015).

Of practical interest to educational developers, when asked to rate the options for future training and support, one-to-one training and online video or screen casting support were the top two choices considered 'very useful' or 'useful'. Online written instructions and guides and one-hour workshops were the next most popular choices with two or three-hour workshops considered the least popular.

Finally, a very positive finding was the response to the question about the future use of online tools. When asked if they would like to make more use of online tools in teaching $91 \%$ $(n=430)$ responded yes and 9\% $(n=45)$ responded negatively (Figure 8$)$. This clearly shows that it is worthwhile investing in supporting teachers to use technology in their teaching in order to encourage innovative and efficient pedagogy, although bringing both together remains a challenge.

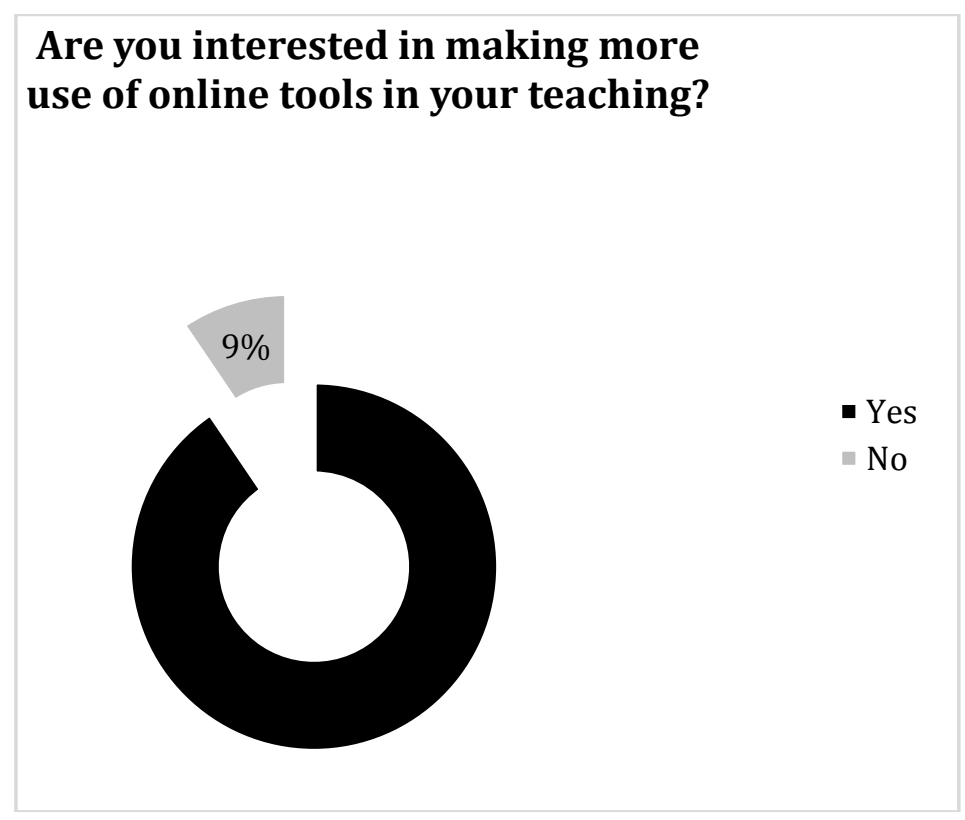

Figure 8: Future use of online tools in teaching

When considered in conjunction with earlier findings indicating conservative use of the VLE and online tools perhaps Laurillard's question "what does the teaching community need to help them personalise learning?" becomes relevant. Indeed, Laurillard suggests that technology provides the opportunity to develop a range of resources for teaching. However, 
she cautions that if learning design remains a "hand-crafted, context-specific exercise" a repetitive and traditional approach will ensue (2008, p. 144). She offers a solution to HE institutes and developers: to make teaching more like research. Focusing on teaching and problematizing, exploring, building on the work of others, being experimental, reviewing, sharing ideas and being part of a community would allow teachers build knowledge about teaching practice using an action research approach (2008, p. 144). Research-informed principles could include Kreber's "scholarship of engagement", Boyer's "scholarship of discovery" and citing Knight, Tait and Yorke (2006) the requirement to treat teaching as "professional learning" (Laurillard, 2008, p. 144). Adopting these approaches may help move teaching beyond an often individually focused exercise to one that which encourages collaborative pedagogy and sharing of practice through the support of a research community. However, this would require resourcing of staff development and the tools, resources and environments to support sharing and exchange of ideas and learning design.

\section{Conclusion}

This article has set out to answer the questions relating to the extent of use of VLEs by HE staff and the barriers to usage to consider the implications for educational developers. In general, respondents report satisfaction with the VLE and consider it useful for their teaching. As reported in Raftery, Farrelly, and Harding (2018), the majority of respondents were positively disposed to VLEs, considering them useful, easy to use and reliable. However, given the low-level usage of features that promote collaboration and peer learning, questions must be asked about how the VLE is used to support learning. This low usage may be explained in part by the barriers to use suggested in this and other studies, such as lack of time and availability of training tailored to needs.

Findings of this study suggest, given the availability of contemporary research into digital literacies, it is timely to consider if the roll-out of VLEs in HEIs has been on an ad hoc basis, and whether this has had a negative impact on usage. Developing a more strategic approach at macro, meso and particularly at micro level with appropriate resourcing is timely.

Although negative effects on student attendance remain a concern for some staff, the majority of respondents did not consider it an issue. The study has shown that overall there is a positive disposition amongst teaching staff to the use of the VLE, although concerns have been raised in relation to usability in addition to the creation of a dependency culture amongst students at a time in their education when there is a focus on developing skills of self-directed learning and their development as autonomous learners. In addition, the reported lack of incentives and training, highlighted in other studies, have been replicated here with implications for resourcing and policy development. Non-users reported similar barriers and in some cases, did not consider the VLE appropriate for the teaching of their subject.

Given the appetite which emerged for making more use of online tools in teaching, a key question emerging which requires further investigation is the role that professional identity and an understanding of learning theory play in designing and implementing pedagogic innovation which moves beyond the use of technologies to maintain the status quo, replicate traditional approaches to teaching and/or to support an increasing administrative load. This in particular sets a challenge to educational developers and HEIs to examine and research the underlying pedagogical issues associated with the development of digital literacies and the use of technology in education thus influencing the development of policies and strategy in 
Irish Journal of Technology Enhanced Learning

Vol 3, Issue 2, 2018

addition to informing the practice of educational developers when supporting staff in the era of the digital turn.

\section{References}

Aviram, R., \& Eshet-Alkalai, Y. (2006). Towards a theory of digital literacy: three scenarios for the next steps. Retrieved from http://www.eurodl.org/materials/contrib/2006/Aharon_Aviram.htm

Bayne, S., \& Ross, J. (2007). The 'digital native' and 'digital immigrant': a dangerous opposition. SHRE Annual Conference, December 2007.

BERA. (2011). Ethical Guidelines for Educational Research. London: British Educational Research Association.

Bonk, C. J. (2004). Perfect eStorm: Emerging Technologies, Enhanced Pedagogy, Enormous Learner Demand, and erased Budgets. London: The Observatory on Borderless Education.

Brownell, S. E., \& Tanner, K. (2012). Barriers to Faculty Pedagogical Change: Lack of Training, Time, Incentives, and Tensions with Professional Identity? CBE-Life Sciences Education, 339-346.

Caruso, J. B., \& Kvavik, R. B. (2005). ECAR Study of Students and Information Technology, 2005: Convenience, Connection, Control, and Learning. Washington: EDUCAUSE.

Retrieved from https://library.educause.edu/resources/2005/10/ecar-study-of-students-andinformation-technology-2005-convenience-connection-control-and-learning

Factors Determining Students' Low Usage... (PDF Download Available). Available from: https://www.researchgate.net/publication/316601856_Factors_Determining_Students'_Low_ Usage_of_Mobile_Tools_in their_English_Vocabulary_Learning [accessed Apr 22 2018]. Clay, J. (2010). eLearning stuff: a five stage model for using the VLE. Retrieved from http://elearningstuff.net/2010/03/20/a-five-stage-model-for-using-the-vle/

Conole, G., \& Alevizou, P. (2010). A literature review of the use of Web 2.0 tools in Higher Education. Retrieved from http://www.heacademy.ac.uk/assets/EvidenceNet/Conole_Alevizou_2010.pdf.

Cosgrave, R.J., Risquez, A., Logan-Phelan, T., Farrelly, T., Costello, E., Palmer, M., McAvinia, C., Cooper, R., Harding, N., Vaughan, N. (2011) Usage and uptake of Virtual Learning Environments and Technology Assisted Learning Tools: Findings from a multi institutional, multi year comparative study. AISHE-J 3(1) Special Issue: papers from EdTech 2009. Retrieved from http://ojs.aishe.org/index.php/aishe-j/issue/view/3

DES. (2011). Higher Education Authority of Ireland. Retrieved from http://www.hea.ie/sites/default/files/national_strategy_for_higher_education_2030.pdf 
European Commission. (2013). Improving the quality of teaching and learning in Europe's higher education institutes. High Level Group on the Modernisation of Higher Education. Luxembourg: European Union.

Farrelly, T., Raftery, D. and Harding, N. (2018): Exploring lecturer engagement with the VLE: findings from a multi-college staff survey. [Special Issue, McAvinia and Risquez]. Irish Journal of Technology Enhanced Learning, 3(2), 11-23.

Farrelly, T., Raftery, D., Harding, N., Risquez, A., O’Grady, M., McAvinia, C., Costello, E., Ryan, D., McSweeney, D., \& Logan-Phelan, T. (2016). VLEs - What Lecturers Want and Do. EdTech 2016, research paper presentation, Law Society, 26th-27th May.

Farrelly, T., Raftery, D., Risquez, A., McAvinia, C., Harding, N., Costello, E., O'Grady, M., Ryan, D., McSweeney, D., \& Logan-Phelan, T. (2015). Exploring lecturer engagement with the VLE: initial findings from a multi-college survey. EdTech 2015, research paper presentation, University of Limerick, 28th-29th May.

Greener, S. (2012). Using Marketing Models to Review Academic Staff Acceptance of Digital Technology to Enhance Learning in Higher Education. 9th International Scientific Conference on Distance Learning in Applied Informatics: Conference Proceedings (pp. 111118). Divai.

Howe, N., \& Strauss, W. (2000). Millennials rising: The next great generation. New York: Vintage Books.

Humphries, J. (2015). Poor infrastructure 'contributing to slip' in university rankings. The Irish Times, $9^{\text {th }}$ March 2015. Retrieved from http://www.irishtimes.com/news/education/institutes-of-technology-warn-against-three-tiersystem-1.2132281

JISC. (2014). Developing digital literacies. Retrieved from https://www.jisc.ac.uk/fullguide/developing-digital-literacies

JISC. (2015). Guide to curriculum chnage. Retrieved from https://www.jisc.ac.uk/guides/developing-digital-literacies/curriculum-change

Jones, C. (2013). The Digital University: a concept in need of definition. In R. Goodfellow, \& M. R. Lea, Literacy in the Digital University: Learning as social practice in a digital world: Critical perspectives on Learning, scholarship and technology (pp. 162-172). London: Routledge.

Knight, P., Tait, J., \& Yorke, M. (2006). The professional learning of teachers in higher education. Studies in Higher Education, 31(3), 319-339.

Laurillard, D. (2008). The teacher as action researcher: using technology to capture pedagogic form. Studies in Higher Education, 33(2), 139-154.

Littlejohn, A., Beetham, H., \& McGill, L. (2013). Digital literacies as situated knowledge practices: academics. In R. Goodfellow, \& M. R. Lea (Eds.), Literacy in the Digital University: Learning as social practice in a digital world : Critical perspectives on learning, scholarship and technology (pp. 126-136). London: Routledge.

McAvinia, C. and Risquez, A. (2018): Editorial: The \#VLEIreland project. [Special Issue, McAvinia and Risquez]. Irish Journal of Technology Enhanced Learning, 3(2), i-ix.

McAvinia, C., Ryan, D. \& Moloney, D. (2018). I don't have the time! Analysing talk of time in lecturers' use of the VLE. [Special Issue, McAvinia \& Risquez]. Irish Journal of Technology Enhanced Learning, 3(2), 54-65. 
McMahon, M. (2016). The Adoption of a Virtual Learning Environment Among "Digital Immigrant" Engineering Lecturers: a Case Study. Irish Journal of Academic Practice, 1-22. Retrieved from https://arrow.dit.ie/ijap/vol5/iss1/3/

Margaryan, A., Littlejohn, A. \& Vojt, G. (2011). Are digital natives a myth or reality? University students' use of digital technologies. Computers and Education, 56, 429-440.

National Forum. (2014). ILTA National Forum Insights. Retrieved from http://www.teachingandlearning.ie/wp-content/uploads/2014/02/ILTA-Forum-Insight.pdf

National Forum. (2017). Ireland's Higher Education Technical Infrastructure A review of current context, with implications for teaching and learning enhancement. (K. O'Rourke, Ed.) Retrieved from https://www.teachingandlearning.ie/wp-content/uploads/2017/12/FinalInfrastructure-report-with-doi-web-ready.pdf

National Forum. (2015). Teaching and Learning in Irish Higher Education: A Roadmap for Enhancement in a Digital World, 2015-2017. Retrieved from www.teachingandlearning.ie: http://www.teachingandlearning.ie/wp-content/uploads/2015/03/Digital-Roadmap-web.pdf

National Forum. (2016). National Professional Development Framework for All Staff Who Teach in Higher Education. Retrieved from www.teachingandlearning.ie:

https://www.teachingandlearning.ie/wp-content/uploads/2016/09/PD-Framework-FINAL.pdf

O'Rourke, K. C., Rooney, P., \& Boylan, F. (2015). What's the Use of a VLE? Irish Journal of Academic Practice, 4(1), 1-19. Retrieved from

https://arrow.dit.ie/cgi/viewcontent.cgi?article=1043\&context=ijap

Oblinger, D. G. \& Oblinger, J.L. (2005). Educating the Net Generation. EDUCAUSE ebook. Retrieved from https://www.educause.edu/ir/library/pdf/pub7101.pdf

Prensky, M. (2010). Teaching digital natives: Partnering for real learning. Thousand Oaks, CA: Corwin Press.

Prensky, M. (2001). Digital Natives, Digital Immigrants. On the Horizon, 9(5).

Raftery, D. and Risquez, A. (2018): Engaging students through the VLE: comparing like with like using the \#VLEIreland student survey. [Special Issue, McAvinia and Risquez]. Irish Journal of Technology Enhanced Learning, 3(2), 24-34.

Risquez, A., McAvinia, C., Raftery, D., O’Riordan, F., Harding, N., Cosgrave, R., LoganPhelan, T., \& Farrelly, T. (2013) An Investigation of Students' Experiences Using Virtual Learning Environments: Implications for academic professional development. In C. O'Farrell and A. Farrell (Eds.) Emerging Issues in Higher Education III: From capacity building to sustainability. p.99-112. Athlone: EDIN. Retrieved from http://www.edin.ie/pubs/ei3chapters/ei3-ch8.pdf

Ryan, D and Risquez, A (2018): 'Lessons Learnt': the student view in the \#VLEIreland project [Special Issue, McAvinia and Risquez]. Irish Journal of Technology Enhanced Learning, 3(2), 1-10. 
Satchwell, C., Barton, D., \& Hamilton, M. (2013). Crossing boundaries: digital and nondigital literacy practices in formal and informal contexts in further and higher education. In R. Goodfellow, \& M. Lea, Literacy in the Digital University: Learning as social practice in a digital world: Critical perspectives on learning, scholarship and technology (pp. 42-55). London: Routledge.

Selwyn, N. (2014a). Distrusting Educational Technology: Critical Questions for Changing Times. Routledge, Abingdon Oxon , UK: Routledge.

Selwyn, N. (2014b). Digital Technology and the Contemporary University: Degrees of Digitization. Abingdon Oxon, UK: Routledge.

Williams, A. (2015, Sept 18). Move Over, Millennials, Here Comes Generation Z. Retrieved from http://www.nytimes.com/2015/09/20/fashion/move-over-millennials-here-comesgeneration-z.html?_r=0

Y1 Feedback. (2016a). Feedback in First Year: A Landscape Snapshot Across Four Irish Higher Education Institutions. Retrieved from http://y1feedback.ie/wpcontent/uploads/2016/04/ALandscapeSnapshot2016.pdf

Y1 Feedback. (2016b). Technology-Enabled Feedback in First Year: a Synthesis of the Literature. Retrieved from http://y1feedback.ie/wpcontent/uploads/2016/04/SynthesisoftheLiterature2016.pdf

Zemsky, R., \& Massy, W. F. (2004). Thwarted Innovation: What Happened to e-learning and Why. Retrieved from

https://www.immagic.com/eLibrary/ARCHIVES/GENERAL/UPENN_US/P040600Z.pdf 